\title{
A Conversation with Gerhard Meisenberg
}

\author{
Grégoire Canlorbe \\ Independent scholar, 75000 Paris, France; gregoire.canlorbe@wanadoo.fr \\ Received: 13 June 2019; Accepted: 15 June 2019; Published: 20 June 2019
}

\section{Introduction}

Gerhard Meisenberg is a retired professor of biochemistry who lives in the Caribbean island nation of Dominica. Originally from Germany, he studied at the universities of Bochum and Munich where he obtained his Ph.D. in biology. He then did biochemistry research in the United States for three years, before joining the faculty at Ross University School of Medicine in Dominica. He worked in Dominica from 1984 until the end of 2018. He became known as the senior author of a major textbook of medical biochemistry that has so far been printed in four editions. In addition, he embarked on research in educational research and psychometrics. His special interest is in secular trends of intelligence (Flynn effects), which he studied in Dominica.

\section{Conversation}

Grégoire Canlorbe:

You are best known for your textbook Principles of Medical Biochemistry as well as your evolutionary psychology treatise In God's Image: The Natural History of Intelligence and Ethics. How do you move from the former to the latter?

\section{Gerhard Meisenberg:}

Biochemistry and the study of human behavior are both part of biology, although at slightly different levels. Psychology is one step down in the "hierarchy of sciences": more complex, and less precise. What attracted me to human behavior are the big questions about why humans are the way they are, how they got that way, and what it means for our ongoing evolution. As Theodosius Dobzhansky famously said, "nothing in biology makes sense except in the light of evolution." I realized that the "big picture" of human history cannot be understood without an understanding of the ongoing evolution of the value systems that determine what aims people pursue and the intelligence that determines how good they are at attaining these aims. Neither of these are etched in stone. They keep evolving, both culturally and biologically.

Grégoire Canlorbe:

A short while ago you co-wrote an article on sex differences in intelligence with Professor Richard Lynn. Could you remind us of the outlines of your perspective on this subject conducive to arousing hysteria?

\section{Gerhard Meisenberg:}

There was actually a big debate about sex differences in the journal Mankind Quarterly, where contributors exposed the different views in the field. Briefly, there are those who hold the view that in modern Western societies there are no sex differences in intelligence that are big enough to have any real-world importance. James Flynn defended this position. The second view is represented by Richard Lynn, who claims that boys and girls start out pretty equal, but from the age of about 15 males gain an advantage over females because their mental as well as physical growth continues to an older age. Lynn estimates that adult men score 3 to 5 IQ points higher than women, which is a very small 
difference. He thinks that, together with a higher male standard deviation, this is sufficient to explain male dominance in many intellectual fields. Then there are those, including myself, who emphasize that males and females have different strengths and weaknesses. For example, males have an up to one standard deviation (15 IQ points) advantage in mechanical reasoning, but females come out on top in tests of emotional intelligence and of verbal and episodic memory. There isn't a huge amount of disagreement among scientists who study these sex differences. It's a matter of emphasis.

Another thing to consider is that sex differences in some non-cognitive traits are much bigger than those in measured intelligence. Some aspects of vocational preferences have sex differences of at least one standard deviation, although this depends much on the way the differences are measured and analyzed. Perhaps the reason why women have lower mechanical comprehension is not that they are innately deficient in this kind of reasoning, but that they have zero interest in the workings of gears and pulleys. Therefore, they never bother to develop the ability to understand these things.

Grégoire Canlorbe:

So, do you think that differences in preferences are more important than differences in intelligence for real-world outcomes, for example, different representations of men and women in different occupations? Some people claim that women are oppressed in traditional societies and even in modern ones.

Gerhard Meisenberg:

People who are oppressed are supposed to be unhappy, true? It means that when you take big international surveys and look at whether men or women claim to be happier and more satisfied with their lives, you would expect that in traditional societies with strict separation of gender roles, women are less happy than men, and in modern egalitarian societies the women are at least as happy as the men. It doesn't work that way. What I found was that women tend to be happier than men in Muslim countries and in countries with low female employment. Perhaps women are happiest in those countries where they don't have to work like the men.

Grégoire Canlorbe:

You mention that there is not much disagreement among scientists studying sex differences. Where does the controversy come from?

\section{Gerhard Meisenberg:}

It comes from non-scientists, specifically those who are high in social dominance orientation. This means, those who think of human relations primarily in terms of dominance hierarchies and power. They can understand intelligence only as an attribute of dominance status. And because people who are high on social dominance orientation are tribalists and highly combative, some will identify with those who are perceived as high-IQ, and others with those who are perceived as low-IQ. Because they can think only in terms of dominance and power, they freak out about IQ differences where others see differences in preferences, and power relations where others see diversity. It's the same with all non-scientific controversies about intelligence.

Grégoire Canlorbe:

The contemporary decline in general intelligence is commonly thought to be the consequence of pornography, reality television, overspecialization, or the cultural disdain for reading and learning. Other interpretations, perhaps less intuitive but quite popular as well, link intellectual decline to the dysgenic fertility following the Industrial Revolution - and the concomitant dissipation of Darwinian pressures-in the white world. Are both opinions true?

\section{Gerhard Meisenberg:}

The question of whether people are getting brighter or stupider is indeed hugely important. You know why? Look at the historical developments of the last 200 or 300 years. What do you see? 
Enlightenment, industrial revolution, lots of discoveries and inventions. And what do you need for discoveries and inventions? You need intelligence! Intelligence was rising during the last century, and probably in the centuries before. We call this the Flynn effect. Intelligence doesn't fall from the sky. It needs to be developed. We even have special institutions to develop children's intelligence. They are called schools. Now, what do you think is going to happen when people get a little more intelligent? They will improve their standard of living. Better nutrition, better schools, better everything. What does this mean for the children? Higher intelligence. With their higher intelligence, these children will improve schools and everything else for their children even more, leading to even higher intelligence. What we call progress is an upward spiral where the Flynn effect and economic growth reinforce each other.

Your diagnosis is correct that we now see an end of the Flynn effect and sometimes a reversal, an anti-Flynn effect, at least in Europe. For the United States we are not sure, and intelligence is rising in most developing countries. Why Flynn effects are ending in the most advanced countries is not clear. Perhaps it's consumerism, dumbed-down school curricula or changing attitudes to learning, certainly not pornography. My guess is that IQ has maxed out simply because we have reached our biological limits. We cannot turn everyone into an Einstein, just as we cannot teach algebra to a chimp. But you see the implication. Once intelligence starts declining, we get a downward spiral. The rise of the West, now in reverse.

You mention dysgenics, meaning the tendency for the less intelligent to out-reproduce the more intelligent. Dysgenics has little immediate impact because the difference it makes in a single generation is small, perhaps one IQ point per generation in the United States today and even less in most European countries. Therefore, people don't notice it, but it is a slow-acting poison that leads to civilizational decline on a time scale of centuries to millennia. What is important is that dysgenics is not limited to the West. We see it in all modern nations, including the advanced ones in Asia. No, we in the West cannot depend on it that someone else will keep up civilization once we have turned ourselves into happy idiots. We are all sitting in the same boat.

Grégoire Canlorbe:

What would be the consequences when intelligence starts declining? How would we notice?

\section{Gerhard Meisenberg:}

Good question. I was wondering about this for a long time. Less innovation, economic stagnation, the demise of the more complex technologies, like manned space exploration. But since 2016, I believe that politics will be affected first. Science and technology are cumulative. Maintaining what is known already is easier than figuring out new ways. People can hang on to old technologies for a couple of generations, even when they are no longer able to improve on them or invent new ones. It's different in politics, and also management and education. Here, declining intelligence means that the changes that are made are more likely for the worse than for the better. It will show as poor decision-making and toxic ideologies.

Grégoire Canlorbe:

Since 2016? Poor decision-making and toxic ideologies? Do you mean Brexit and Trump?

\section{Gerhard Meisenberg:}

Brexit and Trump are only the visible part, the part that makes it into the news. I also mean intersectionality and similar ideologies that have been oozing out of academic grievance studies departments for some time. What alt right and lunatic left have in common is the rejection of science and reason, of Enlightenment values and universalism in favor of nationalism and identity politics. Don't look for the differences. What the warring factions in the culture wars have in common, that's the important part. Today, the most nationalist countries in the West are Britain and the United States, 
and these are also the countries where attacks on intelligence research by self-styled left-wingers are most virulent. This is no coincidence. It's two sides of the same coin.

Grégoire Canlorbe:

You mention nationalism and identity. What role do you see for race and ethnicity in human history? While race is merely a biological category, ethnicity is a bio-cultural formation: in fact, the latter appears to be an emergent property of the former. In the words of Russian philosopher Nikolai Berdyaev (in his 1923's The Philosophy of Inequality), "By itself, race is a natural, biological, zoological, and not historical factor. However, it acts in the historical formations, it plays there even a decisive and secret role. There is indeed in race a mysterious depth, a metaphysics and an ontology of its own. Emerging from the biological sources of life, human races enter the reality of history and act as more complex, historical races (i.e., ethnicities and nations). Different places are devoted to the white and yellow races, the Aryan and Semitic ones, the Slavic and Germanic ones."

\section{Gerhard Meisenberg:}

Forget about this old-time Russian philosopher. The philosophy of race and ethnicity is a waste of time. Scientifically, there are two parts to it. The biological part are differences in allele frequencies. The claim that races don't exist in a genetic sense is bogus. If it were true, we would be unable to determine racial origins from DNA, and someone would already have sued $23 \&$ me and ancestry.com for fraud. The psychological part of it are the tribal instincts, people's need to identify emotionally with this-or-that nation, race, religion, ideology, or football team. Ethnicity, race, traditional religion, and football teams are for simple minds, and ideology is for sophisticates, and the British peerage and the Chinese Communist Party have their own sense of identity, too. There is nothing enduring about all this, except that people associate with those who are similar to themselves.

Grégoire Canlorbe:

Do you not think that the genetic aspects of race have some influence on ethnicity and culture and history? Rushton thought that life history is important.

\section{Gerhard Meisenberg:}

Life history theory is fashionable in some quarters, but I find it too general a concept to be useful. It includes too many traits that correlate only slightly. We should look for differences of a general nature, but not as general as "life history". For example, I noticed that little children in the Carib Territory appear quite shy and reserved, very different from the noisy, boisterous children of the Afro-Caribbeans. Is this a genetically-based race difference? Perhaps. If so, it may well have to do with cultural differences between African and Amerindian communities.

Genetic differences are important for historians. One idea is that even small differences in the genetic potential for higher intelligence, and perhaps also some other traits, can determine whether a population builds a civilization or descends into a Dark Age. First results from ancient DNA suggest that polygenic scores for education/intelligence were rising in Europe during the last 3000 years, and also that in Greece, polygenic scores rose before the classic period and then declined again after. There is also the claim that Chinese thinking is holistic while European thinking is analytical. Who knows, perhaps there is a genetic origin of this. Or perhaps there isn't. We don't know.

Grégoire Canlorbe:

You mention polygenic scores. What are polygenic scores and what do they tell us about race differences?

\section{Gerhard Meisenberg:}

Polygenic scores are measures of genetic predisposition for a complex trait, for example diabetes risk or school achievement. The total count of the trait-increasing genetic variants, or alleles, is the 
polygenic score. There have been many genome-wide association studies (GWAS) for educational attainment and intelligence. The biggest one was based on more than a million subjects. It found that single-nucleotide polymorphisms (SNPs) in more than 1200 genomic regions contribute to these outcomes. This is remarkable. In order to reach genome-wide significance, the difference between the two homozygotes must be at least about half an IQ point. Let's assume we have 1200 variable genes, each contributes half an IQ point, and all these effects are additive. Now let's construct two genetically engineered humans, one homozygous for all the high-IQ alleles and the other homozygous for all the low-IQ alleles. What would be the difference between these two genetically engineered humans? It would be 600 IQ points! Hard to imagine what this would mean. Most likely something like the difference between human and chimp.

The biggest race differences are only something like 15 IQ points when environments are not too different. Even if all of this is genetic, it is tiny compared to the total. It means that there are lots of genes where the high-IQ allele is most common in Africa, and others where it is most common in Europe or China or Melanesia. There can be only very small differences in the grand total. If, say, the average frequency of the high-IQ alleles is 50\% in Europe, perhaps it is $48 \%$ or $52 \%$ in some other parts of the world. The results that I have seen look pretty much like this.

\section{Grégoire Canlorbe:}

You mean, the question of race differences in intelligence is already answered by science because all we need to do is count the frequencies of a few hundred or a few thousand genetic variants in a population?

\section{Gerhard Meisenberg:}

Not quite. One reason is that genomicists are racists. So far, they have included almost exclusively people of European descent in their association studies. Therefore, the polygenic scores we have do not include genetic variation that is specific for non-Europeans. Also, most of the SNPs that come out of the association studies are not causal. They are only genetically linked with the causal ones because they sit next to them on the chromosome. An SNP allele that is linked with a high-IQ causal variant in Europeans can be linked with the alternative low-IQ variant in Africans. The European-derived polygenic scores have only $20 \%$ of the predictive power for Africans that they have for Europeans. White parents can already select their embryos for higher intelligence, but Black parents cannot do this effectively. We already have some idea of which SNPs predict in Europeans only and which ones predict also in Africans, although we cannot be sure because sample sizes for Africans are too small. I have seen recent unpublished results showing that polygenic scores formed only from SNPs that also predict in Africans show race differences, but those that predict only in Europeans don't. There is still a long way to go.

\section{Grégoire Canlorbe:}

There are people who say this kind of research shouldn't be done because it promotes racism. Is this concern justified?

\section{Gerhard Meisenberg:}

What is racism? In Martin Luther King's time, a racist was someone who supports race-based policies to give one race an advantage over the other. Today, those who are called racists invariably are those who want to treat people as individuals rather than as members of a race. I am thinking of scientists and intellectuals like Charles Murray and Richard Lynn. This reversal has taken place among the educated classes in the US and Britain, but not elsewhere. In the Caribbean, there is still a consensus that race should make no difference in the way people are treated. No race-based disadvantages, and no affirmative action either. Therefore, everyone in the Caribbean qualifies as a racist. I have seen the difference between these racisms. My three daughters were the only white children in their school in Dominica, but race has never been an issue. I remember how shocked my oldest daughter was when 
she was visiting the grandparents in Germany, and the old folks reprimanded her for befriending a Moroccan girl who lived in the neighborhood. I very much prefer the Caribbean kind of racism to the traditional German kind, and also to the inverted kind of British and American identity politics.

Also, what exactly is the discovery of genetic race differences in intelligence supposed to promote? European welfare states are based on humanitarian principles, so they have provisions to aid those who are less capable, especially those who are too young, old, sick, or disabled to work. Within the normal range of ability, they use progressive taxation to smoothen out the economic consequences of ability differences. Scientific proof of race differences in intelligence can therefore be used to call for race-based affirmative action. Only, differences in racial averages are so small compared to individual differences that this would be pointless. I remember that some election campaigns ago, Obama said the government should do more to help disadvantaged people, but it should be based on actual disadvantage, not on race. That seemed sane to me.

Contrast this with the Machiavellian types, those really high in psychopathy and social dominance orientation. They have no concept of social welfare and humanitarianism but can understand only power and exploitation. When these kind of people are told that there are race differences in intelligence, they can only understand it as an invitation to exploit and destroy those with lower IQ. Some accept the invitation and become Nazis. Others reject it and become Antifa who battle both the Nazis and the humanitarians.

\section{Grégoire Canlorbe:}

I will need time to digest this, but you seem to distinguish people based on the kind of things they can or cannot comprehend.

\section{Gerhard Meisenberg:}

People can comprehend only what they are able to experience. I learned this from a young man who described himself as asexual. One day he told me a story from his time as a student in America. He said: “ ... I asked my friend: 'What's wrong with that woman? I keep meeting her in the hallway of the dorm, and she talks to me, and then she follows me in my room. I am really bothered.' To this the friend replied: 'Did you not notice? She is in love with you.'” Well, my asexual friend recognized at that point that he had not noticed what was obvious to everyone else because lacking the experience of having been in love, he could not recognize this state in others. To his credit, my friend did not turn into an anti-pornography or anti-sexual harassment crusader, but simply accepted that most others had something that he himself was missing. In the same way, you can deduce the psychological capacities and deficiencies of people from the way they respond to the prospect of race differences in intelligence.

Grégoire Canlorbe:

You are involved with the National IQ database, which compiles average IQs from all countries in the world. You seem to be a pragmatic type, so what does it mean when the average IQ in a country is 80 , or 90 , or 100 ?

\section{Gerhard Meisenberg:}

This project had been started by Richard Lynn at a time when almost nothing was known about average IQs in countries, especially the less developed countries, but by now we have tracked down original IQ studies from about 150 countries. What we have learned is, first of all, that there are large differences between countries, with average IQs all the way from the 50s in the most backward countries up to 110 in Singapore. We know that IQ goes with economic development. The poorer the country, the lower the IQ. This raises the question of cause and effect. Does poverty keep IQ down, or does low IQ maintain poverty? My assumption has always been that both mechanisms are important. That's why I understand "progress" as an upward spiral, where higher intelligence and economic development reinforce each other-and civilizational collapse is the same process running in reverse. 
Grégoire Canlorbe:

There has been a good deal of criticism of the international IQ data. They have been claimed to be meaningless, and there has been special criticism of the African IQs. How has the field weathered these criticisms?

Gerhard Meisenberg:

The "meaning" of these data becomes clear when you look at their closest correlate: results in the OECD's PISA [Organisation For Economic Co-operation And Development's Programme For International Student Assessment] studies, which assess scholastic achievement of 15-year-olds in science, reading, and math. The country-level correlation between PISA scores and IQ is so high that we are dealing pretty much with the same construct. PISA tests and IQ tests both measure intelligence. Differences between countries are smaller for IQ than for PISA scores, though. You can say that IQ tests are less "culturally biased" than PISA tests. Also, IQs are available for many countries that never participated in PISA. For example, not a single country of Sub-Saharan Africa has ever participated in PISA, but we have IQs for many of them. The international IQ data are important mainly as a resource for educators in developing countries.

The African IQs collected by Lynn were indeed criticized by Jelte Wicherts and others many years ago. These authors claimed that the average African IQ was not 70, as claimed by Lynn, but in the low 80s. Actually, most of the African IQs I have seen are way below 70, outside the norming range of the IQ tests. It would indeed be astonishing if the average IQ in Africa were above 80. This would be almost as high as the average IQ of African Americans. Because schooling is the most important environmental factor for children's intelligence, such a high IQ would imply that African schools are already almost as efficient as American schools, and further efforts to improve African school systems are not needed. Fortunately, development economists and educators in Africa didn't take the claim of high African IQ seriously. They know better.

Grégoire Canlorbe:

You mention average IQs way below 70. Are you sure? Everything below 70 is considered mentally retarded.

\section{Gerhard Meisenberg:}

Being mentally retarded is the natural state of the human mind. Medieval Europeans who believed in witches riding through the air on their brooms almost certainly would flunk any modern IQ test, and that's what we see with semi-literates in developing countries today. I have seen it when I tested older people in Dominica, although young people had no difficulty at all with the tests. The kind of analytical thinking that is needed for IQ tests and in school is alien to unschooled people in traditional societies. As a biologist, I would argue that any IQ above 70 is pathological because populations with IQ above 70 invariably adopt contraceptive habits which drive the population toward extinction. Also, contraception is adopted first by those with more intelligence and foresight, those with a greater sense of control over their lives. This is a reason why race differences in intelligence are so small. Under backward, low-IQ conditions, natural selection favors higher intelligence, and under advanced, high-IQ conditions it favors lower intelligence. There is a sweet spot where people are bright enough to survive but too stupid to control their fertility, and this is the same everywhere in the world.

\section{Grégoire Canlorbe:}

In view of their moderate psychoticism and their inability to deal with ordinary day-to-day affairs, geniuses seem to do poorly under a regime of individual selection. Nonetheless they prove to be eminently adapted under a regime of group selection, at least under what may be called an individualist regime of group selection in which independent thinking-and therefore self-assertiveness-are 
encouraged in virtue of their providing the bio-cultural group with alternative conceptions to solve the problems facing the latter.

It may be argued that in ancient Greece, Athens was the model par excellence of an individualist regime of group selection, while Sparta was the most eminent model of a conformist regime of group selection (for which social cohesion and the self-sacrifice of the individual in the interest of the group are priority). To what extent do you believe that geniuses are actually disappearing in contemporary Western society? Do you link their extinction to the attenuation of group selection pressures-or do you think that the phenomenon rather has something to do with the West transitioning from an individualist regime of group selection to one more detrimental to geniuses?

\section{Gerhard Meisenberg:}

The whole genius concept smacks of hero worship. I don't think we can easily quantify genius, but I am also getting the impression that radically new ideas that are not lunacy or hype are drying up slowly. Where we still see massive progress is in technology-driven fields such as genomics and Artificial Intelligence (AI). Group selection is not a terribly useful concept. First, what kinds of groups do you have in mind? Nations, religions, social classes, or what? War is a prototypical form of group selection: a band of males killing males from a different tribe or village. The brighter, stronger, more aggressive or more cooperative bands win out and scatter their genes.

But it didn't work like that in later times. In the Middle Age, aristocrats slaughtered each other in war while peasants stayed at home and survived. In the early modern age, selection was completely different when princes sold their paupers as cannon fodder for warring armies. Calling any of this group selection would be a stretch. No, in Europe, useful traits like intelligence and self-control were favored by individual selection, not group selection. This is what Gregory Clark called the survival of the richest. It means that the poor could not afford to marry and raise children. Conditions were similar in Asian countries, although family planning in Asia was not by late or foregone marriage, but by infanticide.

Sparta shows that the militarist form of group selection didn't work even then. There were the Spartan nobles who did the fighting, and the helots who did the labor. What killed Sparta was the failure of the nobility to maintain their numbers. Their birth rate was unimpressive in the best of times, and there were recurrent war casualties. It is not clear what traits were selected under these conditions, but the Spartans were not known for an abundance of geniuses.

A dearth of geniuses today is expected because there has been selection for lower intelligence since the demographic transition. High intelligence really is pathological. The brighter and more open-minded adopted effective contraception first. Later, they made up anti-natalist ideologies that kept bright women from having children. As a result, there was a slow erosion of the genetic potential, but this was more than offset by strong Flynn effects. Geniuses disappear when the Flynn effect reaches its limits while the genetic potential continues declining, not only in the modern West, but everywhere.

\section{Grégoire Canlorbe:}

You are currently investigating the evolutionary underpinnings of conservative and progressive worldviews. Might Jesus have inflicted on the Hebrews of his time what "liberal" Jews are nowadays inflicting on Western nation-states-including modern Israel?

\section{Gerhard Meisenberg:}

Jesus was a liberal by the standards of his time and place, although St. Paul is considered a homophobic reactionary. What you have in mind is Kevin MacDonald's theory that liberal Jewish intellectuals undermine modern societies with corrosive ideologies like communism, psychoanalysis, and multiculturalism. Here, I rather side with the critique of Nathan Cofnas, who proposes the default hypothesis that Jews, and specifically the Ashkenazim, are simply very bright and are therefore overrepresented in all intellectual movements. Jews do indeed have higher polygenic scores for $\mathrm{IQ} /$ education than Gentiles. At this point, higher Jewish intelligence is the only racial or ethnic 
difference in intelligence for which polygenic scores have provided rather convincing evidence. This is because the genetic backgrounds of European Jews and Gentiles are so similar that we need not worry about confounding factors such as different linkage phase between the GWAS hits and the causal variants.

Perhaps there is indeed a tendency for Jewish thinking to be progressive rather than conservative. The Ashkenazim were entrepreneurs by necessity, not civil servants, military officers, or estate owners. Entrepreneurs must be open-minded and inventive to make use of new business opportunities, so perhaps they were selected not only for high intelligence but also for creativity and mental flexibility. These traits now predispose them to liberal and progressive ideologies.

If you think that Christianity was the prototype destructive Jewish ideology, don't forget that it was Christianity that brought Europe from the Dark Age all the way through the Renaissance and scientific revolution to the present. Far from undermining the societies that adopted it, Christianity made them the rulers of the world.

Grégoire Canlorbe:

You are not unfamiliar with the historical patterns of selection on cognitive and life history traits in North Africa and the Middle East. Do you see a combination of authoritarian secularism and state eugenics saving the Islamic world-including not only the Arab ethnicity but the Turks, the Berbers, or the Iranians-from its a-thousand-years-old decay?

\section{Gerhard Meisenberg:}

You are not alone in diagnosing the decay of Muslim civilization. In Haroun al Rashid's time, around $800 \mathrm{AD}$, the Middle East was a world leader politically, culturally, and economically, at a time when Europe and China were just beginning to creep out of their Dark Ages. Since then, Muslim civilization has been falling apart. Historians blamed it on Mongol incursions or on the shift toward rigid dogmatism in Muslim theology, and economists, such as Timur Kuran, on weak economic institutions. All of this is unconvincing. Military defeat, dogmatism, and weak institutions are more likely symptoms than causes of decline.

My favored explanation is that Islam not only permitted contraception, but effective contraceptive practices were indeed widespread in Medieval Islam. Basim Musallam wrote a book Sex and Society in Islam, where he documented this. Today, we observe that whenever contraceptive practices are adopted in a country, the relationship of fertility with social status and education flips from positive or neutral to negative. There is hardly any exception. If the same happened to Medieval Islam, protracted decline of the civilization is the predicted outcome.

Compare this with Medieval Europe. Here, the Church condemned contraceptive practices of any kind. And because the more intelligent have more foresight and discount the future less, they were the ones who were most aware of the post mortem consequences of sinful behavior, so they avoided contraception the most. The important point is that in Europe, the widespread adoption of contraception, and the start of dysgenic fertility, were delayed until after the industrial revolution and the start of the Flynn effect. We should dig up some ancient graveyards from Europe and the Middle East and compare the ancient polygenic scores with those of the people living in these countries today! Grégoire Canlorbe:

It is apparent from your work that the best metaphor to modelize the human being is-in your eyes-that of a crudely programmed computer. When it comes to modelizing the processes of cosmic evolution and "natural selection" in turn, what is the most appropriate metaphor which comes to your mind? Might it be the computer as well?

\section{Gerhard Meisenberg:}

The natural laws are the same for humans and for everything else in the universe. It is also obvious that once living things arise, and this means things that are capable of reproducing themselves, 
there will be evolution by natural selection. This is because reproduction is subject to errors, we call them mutations, and natural selection acts on them. All non-intelligent life in the universe is subject to natural selection, not only life on Earth.

Grégoire Canlorbe:

What about intelligent life? Are you implying that humans no longer evolve by natural selection? Is it because biological evolution has been replaced by cultural evolution, as some have claimed?

Gerhard Meisenberg:

Cultural evolution does not replace biological evolution. Culture speeds up biological evolution because it creates "unnatural" conditions to which we have not yet been adapted by natural selection. High intelligence, boosted by education, is one such unnatural condition. Present-day humans are not what I mean by an intelligent species. The difference between ordinary animals and an intelligent species is that only intelligent life forms control their own evolution. They engineer their own mutations based on predicted effects. And instead of depending on natural selection to throw out the bad mutations and keep the good ones, they sequence the genomes of embryos and decide which ones should live and which ones should be discarded. Natural selection is barbaric. It discards sentient beings, not only embryos.

Every species in the universe that reaches this cognitive threshold has to make some key decisions: continue as a species, or opt for extinction? Continue as a single species, or split up into several species? If it decides to continue, there are innumerable decisions about what traits the species should have. Make everyone alike, or have genetically-based races or castes, like in Aldous Huxley's Brave New World? Present-day humans are odd. They can already decide what kind of racehorses, broiler chickens, and toy dogs they want, and so they breed them, but they don't have a concept of what kind of species they themselves want to be and how to achieve this. Humans seem to lack meta-cognitive skills of deliberating and deciding what their desires, preferences, and values should be, nor do they have the ability to control these traits. Human thinking evolved for understanding and manipulating the outside world but not itself, the way the eye evolved to see the world but not itself.

Grégoire Canlorbe:

Thank you for your time. In view of your recent displacement by a hurricane in the Caribbean, how do you assess the way a "cosmic shock," or a "black swan," may upset previously stable and regular life history traits?

Gerhard Meisenberg:

This was hurricane Maria hitting Dominica in September 2017. The devastation was complete: most buildings with damaged or missing roofs, people drying their soaked matrasses and clothes beside their destroyed wooden homes the day after the hurricane, the electrical grid wiped out, bridges destroyed, acute shortages of fuel, food, everything. And yet, looking at how people responded to it, within days the experience had reinforced my conviction that natural disasters are nothing much to worry about. No matter how bad the damage, it can be fixed. The problems are not hurricanes, but people. Indeed, the hurricane damage got repaired in little more than a year, with generous help from outside: teams from Barbados, Cuba, St. Lucia, and other places helping the Dominicans restore the electrical lines, and other help coming in, but the Ross University management gave up on the island. The school left Dominica, never to return. The reconstruction showed the best in human cooperation, while the rats were leaving a ship they falsely thought was sinking.

Those who like to worry about existential risks should not concern themselves with hurricanes or global warming. It's the failings of people that they should worry about. What can global climate change and sea level rise do to us? Nothing that we cannot handle if it comes at a time when human ingenuity is high and people cooperate globally. If anything, it will speed up innovation. But if it hits 
at a time when people are stupid and selfish, caught up in trade wars, culture wars, and real wars, it will speed up the decline and contribute to civilizational collapse.

For starters: Modern societies are not sustainable demographically. Virtually all nations with average IQ above 90 are in sub-replacement fertility, and almost every one of them has an inverse relationship between fertility and education. We already know that average polygenic scores for education and intelligence are declining in many places, and Flynn effects have ended in these countries or are going in reverse. This is not limited to Western countries. It's exactly the same in the more developed Asian countries. We don't know if today's developing countries will ever reach or exceed the level of intelligence and civilization that we now have in the leading-edge countries. Try to predict developments over the next 2 or 3 centuries based on current trends, and you see where the existential threats are.

Funding: This research received no external funding.

Conflicts of Interest: The authors declare no conflict of interest.

(C) 2019 by the author. Licensee MDPI, Basel, Switzerland. This article is an open access article distributed under the terms and conditions of the Creative Commons Attribution (CC BY) license (http://creativecommons.org/licenses/by/4.0/). 